\title{
Cancelled surgeries and payment by results in the English National Health Service
}

\section{Bryan Mclntosh, Graham Cookson', Simon Jones ${ }^{2}$}

Richmond, the American International University in London; ${ }^{1}$ Department of Management; ${ }^{2}$ Division of Women's Health, School of Medicine, King's College London, London, UK

Objectives: To model the frequency of 'last minute' cancellations of planned elective procedures in the English NHS with respect to the patient and provider factors that led to these cancellations.

Methods: A dataset of 5,288,604 elective patients spell in the English NHS from January $1^{\text {st }}, 2007$ to December $31^{\text {st }}, 2007$ was extracted from the Hospital Episode Statistics. A binary dependent variable indicating whether or not a patient had a Health Resource Group coded as S22 - 'Planned elective procedure not carried out' - was modeled using a probit regession estimated via maximum likelihood including patient, case and hospital level covariates.

Results: Longer waiting times and being admitted on a Monday were associated with a greater rate of cancelled procedures. Male patients, patients from lower socio-economic groups and older patients had higher rates of cancelled procedures. There was significant variation in cancellation rates between hospitals; Foundation Trusts and private facilities had the lowest cancellation rates.

Conclusions: Further research is needed on why Foundation Trusts exhibit lower cancellation rates. Hospitals with relatively high cancellation rates should be encouraged to tackle this problem. Further evidence is needed on whether hospitals are more likely to cancel operations where the procedure tariff is lower than the S22 tariff as this creates a perverse incentive to cancel. Understanding the underlying causes of why male, older and patients from lower socio-economic groups are more likely to have their operations cancelled is important to inform the appropriate policy response. This research suggests that interventions designed to reduce cancellation rates should be targeted to high-cancellation groups.

\section{Introduction}

In 2007, there were over 5.9 million elective procedures performed by the NHS. Approximately 3 per cent of them were cancelled after the patient was admitted to the hospital in what is termed a 'last minute' cancellation. ${ }^{1}$ There is an emerging consensus in the literature that cancelling operations increases costs, decreases efficiency, duplicates workload, and wastes theatre time ${ }^{2}$ There is also a considerable impact upon the patient and their family both emotionally and economic., ${ }^{3,4}$ Mangran $^{5}$ estimates that the loss of theatre time is the largest cost of cancelled procedures.

Bryan McIntosh PhD, Associate Professor of International Business, Richmond, the American International University in London, 16

Young Street, Kensington, London W8 5EH; Graham Cookson PhD, Lecturer in Economics, Department of Management; Simon Jones PhD, Visiting Professor, Division of Women's Health, School of Medicine, King's College London, London, UK

Correspondence to: bryan.mcintosh@Richmond.ac.uk
Retrospective hospital-level studies on the causes of cancelled operations are consistent, finding a small but persistent proportion of procedures which are cancelled for clinical reasons after the patient has been admitted.$^{6-11}$ However the literature shows that nonclinical reasons dominate last minute cancellations, with a lack of post-operative bed or theatre time being the most common non-clinical causes (see Dexter ${ }^{12}$ et al. a review). An Australian study found that nonclinical causes accounted for 52 per cent of last minute cancellations, with lack of theatre time $(19 \%$ and lack of a postoperative bed $(18 \%)$ the main causes. ${ }^{13}$ In the US, studies have found cancellation rates for non-clinical reasons to as high at 67 per cent without pre-operative assessment and up to 81 per cent with an assessment clinic. ${ }^{13,14}$ Evidence from the UK is more limited with most research investigating all cancelled operations (i.e. not just last minute cancellations). For example, Sanjay et al. ${ }^{15}$ find that an inconvenient appointment was the most common cancellation reason 
(19\%) followed by list over-run (16\%) in a Welsh hospital.

Cancelled surgical procedures are frustrating for patients, are a source of waste for hospitals and healthcare purchasers and, unlike other inefficiencies in health care, are potentially remediable. ${ }^{4,5,16}$ In the English NHS, procedures that are cancelled after the patient is admitted receive a particular health care resource group (HRG) code for a 'Planned procedure not carried out' ${ }^{17}$ with an associated tariff of $£ 432$ in 2007. Therefore in 2007 alone, hospitals were reimbursed almost $£ 70$ million for cancelling operations at the last minute.

The extant literature on cancelled operations focuses on hospital or theatre level studies of cancellation rates and their causes. This paper adds to the literature by investigating the patient, case and provider characteristics which predict the probability of an operation being cancelled at the last minute using data on every elective procedure in the English NHS in 2007. Our findings lead to a number of recommendations and also highlight areas for future research.

Where procedures are cancelled for non-clinical reasons, the $£ 432$ reimbursement is likely to be greater than the cost to the hospital as the hospital is receiving payment for performing procedures on other patients. Alternatively, where procedures are cancelled for clinical reasons, the opportunity cost of cancelling the operation may exceed the $£ 432$ reimbursement. We discuss some potential implications of the Payment by Results tariff for the rate of last minute cancellations.

\section{Methods}

A retrospective study of population-wide, patient level data using a maximum likelihood probit model was applied examining 5,288,604 elective patient spells in the English NHS from January 1 ${ }^{\text {st }}, 2007$ through December $31^{\text {st }}$, 2007. National hospital activity data from the NHS hospital episode statistics accessed via the NHSWide clearing service for all elective procedures. The data were processed and cleaned by the Dr. Foster Unit and stored by Dr. Foster Intelligence, a private data holding company located in London. The dataset included virtually every elective procedure performed in the NHS during 2007.

The frequency of patients having an HRG code of 'S22', which indicates that a planned procedure was cancelled after a patient was admitted for care ${ }^{18}$ was critical to this examination. After presenting basic descriptive statistics, maximum-likelihood probit models to analyse the influence of patient characteristics, hospital characteristics, and a time vector on the likelihood of a last minute cancellation occurring were applied. S22 codes were the most readily accessible and universally accurate means of analysing cancelled procedures in the NHS. Since HRGs are tied to hospital reimbursement, they tend to be accurately coded across most hospitals. Episodes are converted to spells for this paper, so the unit applied for the National Tariff matches the unit of observation in the administrative data. As part of this process, an admission as an S22 is treated as if it is a single episode spell with an HRG of S22. As such, the dependent variable in our models was a binary indicator for whether a patient's HRG code was coded as an S22.

The patient characteristics included in this model were the patient's gender, age, ethnicity, area of residence, socio-economic status, waiting time and diagnosis chapter heading based on International Classification of Diseases (ICD) 10. A patient's socioeconomic status was based on the socio-economic quintile of the area where the patient lived, measured using the income component of the 2004 index of multiple deprivation (IMD) at the super output area ${ }^{19}$ (For a comprehensive description of the IMD, see Jordan \& Martin ${ }^{20}$ ). Waiting times were measured as the time from when the patient was referred for surgery until the time the patient was admitted for the surgery. Logged waiting times in our analysis because patient waiting times were not normally distributed were used.

Provider information included binary indicator variables for whether the admitting hospital was a teaching hospital, a specialist hospital (i.e. orthopedics only), privately owned, an NHS Treatment Centre (which focuses exclusively on specialties like orthopedics) or had Foundation Trust status. In England, hospitals are awarded Foundation Trust status if they meet a number of managerial, fiscal and quality measures. ${ }^{21}$ These hospitals, approximately $25 \%$ of the sample, are rewarded with greater managerial and fiscal autonomy.

A time vector with dummies for the month and day of week the patient was admitted was included. Robust standard errors in analysis and error terms were clustered around trusts. Observations were excluded from analysis if the diagnosis that drove the admission was related to mental health or infectious disease. Operations were classified based on the dominant ICD-10 codes. Admissions driven by a mental health diagnosis were excluded due to beliefs that they were atypical from traditional clinical admissions. Procedures with a diagnosis related to infectious disease because were excluded due to the possible externalities created from the public health implications of infectious diseases created potential additional pressure to avoid cancellations. Any observations with missing data, such as patients' socio-economic status or waiting times were excluded. There was no correlation between missing data and particular providers, local area characteristics, patient characteristics, or the rate of cancellation. Missing data appeared to be the result of spurious coding errors. Observations were also excluded if the procedure was performed by a 
primary care trust (PCT) acting as a provider, if the patient's waiting time was greater than a year or if the provider performed fewer than 500 procedures per year. It was assumed that any case with a PCT acting as a provider, with a wait of over a year or with a provider who performed a small number of surgeries was atypical and should not influence the overall results.

This analysis relies on administrative data. While administrative data is relatively easy to acquire, encompasses the whole English population, and is computer readable, there are often discussed short-comings which may include data miscoding, missing data, and few measures of process quality. However, it is unlikely that missing data or miscoding would lead to the clear, consistent and statistically significant results that were observed. While a large number of observations were missing waiting times, the cancellation rates of procedures with missing waiting times were no different than cancellation rates for observations with recorded waiting times. Second, because cancelled operations are coded as S22 rather than as the procedure which was originally planned, there was no way of knowing what procedure was scheduled to be carried out. It would have been ideal to control of the type of procedure planned. Instead, patient's primary ICD 10 diagnosis is relied upon.

\section{Results}

The dataset included 6,385,648 observations of NHS patients from January $1^{\text {st }}, 2007$ through December $31^{\text {st }}, 2007$ treated in NHS and private facilities. One thousand, nine hundred and thirteen observations $(0.03 \%)$ were excluded because they were missing information on their ICD-10 diagnosis, 975,875 (15\%) were excluded because they were missing waiting times, 86,663 (1\%) were excluded because they had waiting times greater than one year, and 32,249 $(0.51 \%)$ were excluded because they were missing data on patients' socio-economic status, measured using income component of the 2004 Index of Multiple Deprivation. A further 344 cases $(0.005 \%)$ were removed because they had mental health or infectious disease diagnostic coding. After those amendments, there were 5,288,604 observations include in our analysis. Basic descriptive statistics of the sample are presented in Table 1.

Of the 5,288,604 observations we analysed, 160,842 (3\%) patients were admitted, but had their planned elective procedure cancelled. There was significant variation in the cancellation rates between hospitals as Figure 1 illustrates.

The hospital with the highest rate of cancelled planned elective operations had a cancellation rate over 700 times higher than the hospital with the lowest cancellation rate.
Table 1 Descriptive statistics

\begin{tabular}{|c|c|c|}
\hline \multirow{2}{*}{$\begin{array}{l}\text { Number of Observations } \\
\text { Dependent Variable }\end{array}$} & \multicolumn{2}{|l|}{$5,288,604$} \\
\hline & Mean Value & Standard Error \\
\hline $\begin{array}{l}\text { S22 (Cancelled Procedures) }{ }^{1} \\
\text { Explanatory Variables }\end{array}$ & 0.030 & 0.0000747 \\
\hline Logged Waiting Time & 3.38 & 0.0005791 \\
\hline Female & 0.532 & 0.00217 \\
\hline Age $0-9$ & 0.043 & 0.0000887 \\
\hline Age $10-19$ & 0.040 & 0.0000904 \\
\hline Age $20-29$ & 0.061 & 0.0001068 \\
\hline Age $30-39$ & 0.090 & 0.0001246 \\
\hline Age $40-49$ & 0.130 & 0.0001463 \\
\hline Age $50-59$ & 0.155 & 0.0001573 \\
\hline Age $60-69$ & 0.195 & 0.0001723 \\
\hline Age $70-79$ & 0.180 & 0.000167 \\
\hline Age $80-89$ & 0.088 & 0.0001234 \\
\hline Age 90 and up & 0.008 & 0.0000392 \\
\hline Deprivation $\mathrm{I}^{2}$ & 0.191 & 0.000171 \\
\hline Deprivation $\|^{2}$ & 0.202 & 0.0001746 \\
\hline Deprivation $\mathrm{III}^{2}$ & 0.204 & 0.0001755 \\
\hline Deprivation IV² & 0.204 & 0.0001755 \\
\hline Deprivation $\mathrm{V}^{2}$ & 0.197 & 0.000173 \\
\hline Indian ${ }^{3}$ & 0.027 & 0.0000704 \\
\hline Black $^{4}$ & 0.017 & 0.0000568 \\
\hline Chinese $^{5}$ & 0.002 & 0.0000196 \\
\hline White ${ }^{6}$ & 0.771 & 0.0001826 \\
\hline Other ${ }^{7}$ & 0.004 & 0.0000818 \\
\hline Unknown $^{8}$ & 0.145 & 0.0001533 \\
\hline Foundation Trust & 0.246 & 0.0001872 \\
\hline Teaching Hospital & 0.214 & 0.0001785 \\
\hline NHS Treatment Centre & 0.010 & 0.0000435 \\
\hline Private Facility & 0.012 & 0.0000473 \\
\hline Specialist Hospital & 0.039 & 0.0000845 \\
\hline Traditional NHS Provider & 0.537 & 0.0002168 \\
\hline All Other Diagnosis ${ }^{9}$ & 0.056 & 0.0001005 \\
\hline Neoplasms ${ }^{9}$ & 0.172 & 0.0001644 \\
\hline Endocrine System ${ }^{9}$ & 0.014 & 0.0000524 \\
\hline Musculoskeletal $^{9}$ & 0.128 & 0.0001456 \\
\hline Blood $^{9}$ & 0.019 & 0.0000599 \\
\hline Nervous System ${ }^{9}$ & 0.025 & 0.0000683 \\
\hline Eyes $^{9}$ & 0.094 & 0.0001275 \\
\hline Circulatory $^{9}$ & 0.064 & 0.0001066 \\
\hline Symptoms and Signs ${ }^{9}$ & 0.029 & 0.0000734 \\
\hline Respiratory ${ }^{9}$ & 0.031 & 0.0000758 \\
\hline Digestive & 0.183 & 0.0001684 \\
\hline Genito Urinary ${ }^{9}$ & 0.109 & 0.0001355 \\
\hline Pregnancy Related $^{9}$ & 0.017 & 0.000057 \\
\hline Skin $^{9}$ & 0.024 & 0.0000671 \\
\hline Congenital Malformations $^{9}$ & 0.012 & 0.0000475 \\
\hline Prenatal Period $^{9}$ & 0.000 & 6.99E-06 \\
\hline Injuries and Poisoning 9 & 0.015 & 0.000054 \\
\hline
\end{tabular}

${ }^{1} \mathrm{~S} 22=1$ if the procedure was cancelled; $\mathrm{S} 22=0$ if the procedure carried on as planned

${ }^{2}$ Deprivation was measured using the 2007 IMD income component

${ }^{3}$ Indian includes individuals with Indian, Pakistani, Bangladeshi, Asian or Asian British ethnicity

${ }^{4}$ Black includes individuals with Black Caribbean, Black African, Black British or other Black ethnicities

${ }^{5}$ Chinese includes individuals of Chinese ethnicity

${ }^{6}$ White includes individuals with British, Irish or other white ethnicities ${ }^{7}$ Other includes individuals from mix or other ethnic groups

${ }^{8}$ Unknown includes individuals who did not give, did not know or did not state their ethnicity.

${ }^{9}$ These diagnosis categories are based on the ICD 10 chapter headings composed by the World Health Organization

*Percentages do not add up to 1 , because of rounding

Figure 2, a funnel plot depicting cancellation rates relative to hospitals' elective admissions, demonstrates 


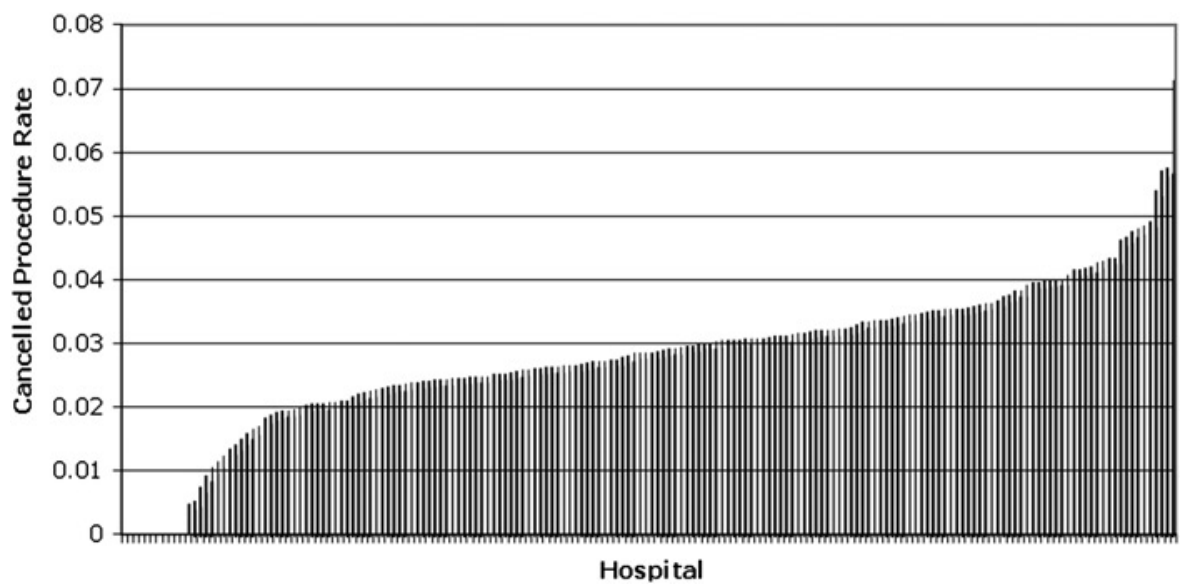

Figure 1 Cancelled Procedure Rate Broken Down By Hospitals

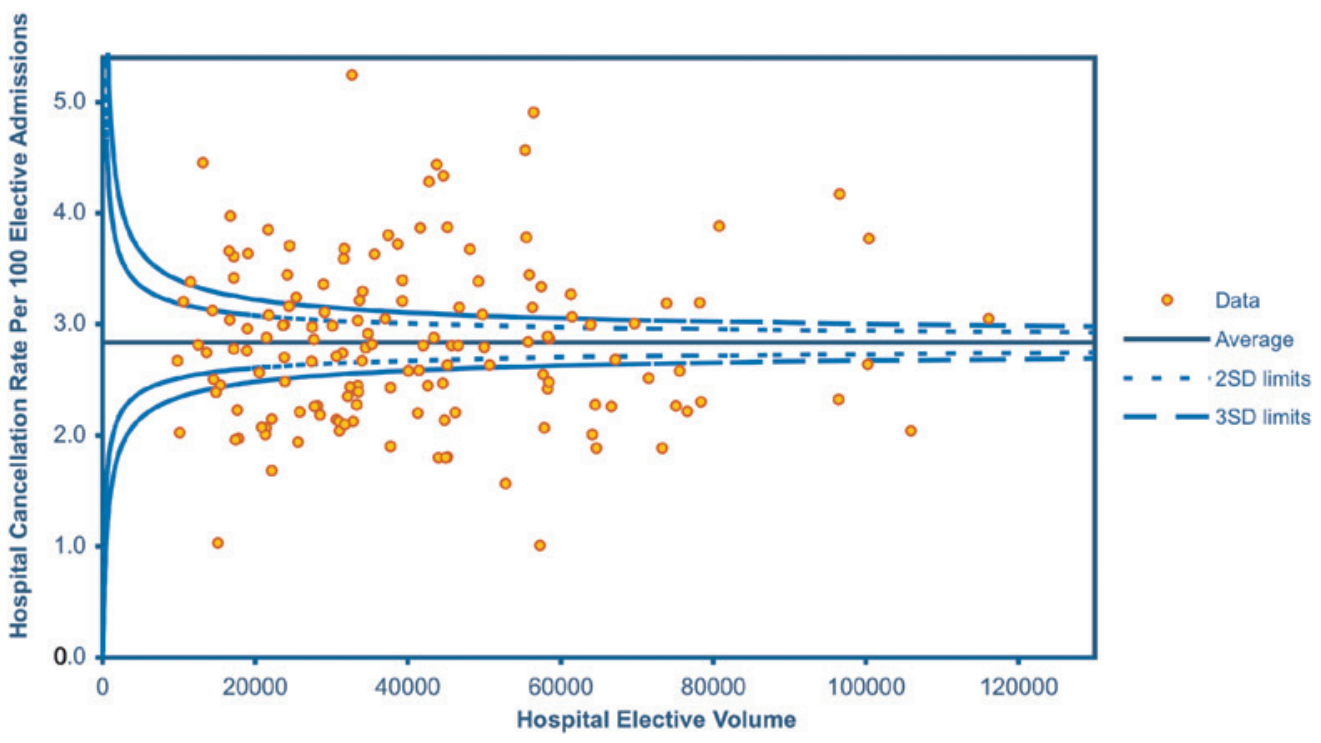

Figure 2 Funnel Plot of Hospital Cancellation Rates Relative to Elective Volume

that the variation in last minute cancellations is vastly greater than what could be expected from simple sampling error alone. There was a statistically significant difference in the last minute cancellation rates between different types of hospitals. Without controlling for their patient population or other supply side characteristics, private facilities cancelled less than half of a percent of patients after they were admitted for care and cancelled significantly fewer procedures than other types of providers. In comparison, traditional NHS providers cancelled approximately $3 \%$ of patients after they were admitted for care. The differences between the cancellation rates at the different types of facilities, illustrated in Figure 3, were significant at $p<0.01$.

Table 2 presents the results from the maximumlikelihood probit model. The dependent variable is equal to one if the patient's procedure was cancelled.
As Table 2 illustrates, a rise in waiting times led to a statistically significant rise in the likelihood of a procedure being cancelled. Men were more likely to have a procedure cancelled than women. Each drop in socioeconomic quintiles, from most-advantaged to leastadvantaged, was associated with an increase in the rate of cancelled procedures. Patients scheduled and admitted for a procedure on a Monday had the highest rates of cancellation. Confirming our descriptive statistics, private providers, Foundation Trust hospitals and NHS treatment centres had lower cancellation rates than traditional NHS facilities.

\section{Discussion}

The analysis suggests that 'last minute' cancellations are a serious problem for the NHS. In the patient population analysed, which captures nearly every NHS 


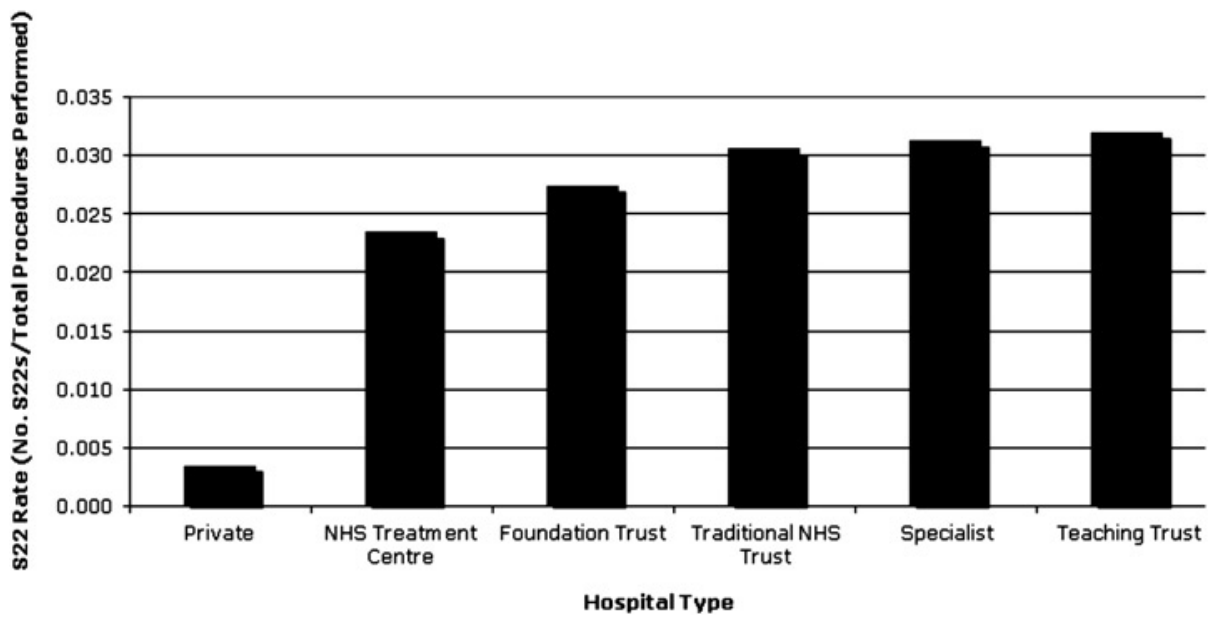

Figure 3 Cancellation Rates, Broken Down by Hospital Type

Table 2 Regression results for probit model

\begin{tabular}{|c|c|c|c|}
\hline & Coef. $(95 \% \mathrm{CL})$ & Standard errors & Z-Statistic \\
\hline Log Waiting Time & $0.073^{* *}(0.065$ to 0.081$)$ & 0.004 & 17.31 \\
\hline Female & $-0.056^{* *}(-0.64$ to -0.048$)$ & 0.004 & -13.5 \\
\hline Deprivation II & $0.017^{* *}(0.007$ to 0.027$)$ & 0.005 & 3.39 \\
\hline Deprivation III & $0.039 * *(0.027$ to 0.051$)$ & 0.006 & 6.12 \\
\hline Deprivation IV & $0.066^{* *}(0.052$ to 0.080$)$ & 0.007 & 9.21 \\
\hline Deprivation V & $0.120 * *(0.102$ to 0.138$)$ & 0.009 & 12.72 \\
\hline Indian & $0.056^{* *}(0.026$ to 0.086$)$ & 0.015 & 3.82 \\
\hline Black & $0.053^{* *}(0.023$ to 0.083$)$ & 0.015 & 3.6 \\
\hline Chinese & $0.041(-0.004$ to 0.087$)$ & 0.023 & 1.81 \\
\hline Other & $-0.032(-0.081$ to 0.017$)$ & 0.025 & -1.29 \\
\hline Unknown & $-0.036^{* *}(0.056$ to 0.016$)$ & 0.010 & -3.55 \\
\hline Age $0-9$ & $0.019(-0.023$ to 0.060$)$ & 0.021 & 0.92 \\
\hline Age $10-19$ & $-0.044^{* *}(-0.076$ to -0.012$)$ & 0.016 & -2.7 \\
\hline Age $20-29$ & $0.010(-0.006$ to 0.026$)$ & 0.008 & 1.22 \\
\hline Age $30-39$ & $0.001(-0.011$ to 0.013$)$ & 0.006 & 0.22 \\
\hline Age $50-59$ & $-0.001(-0.011$ to 0.009$)$ & 0.005 & -0.16 \\
\hline Age $60-69$ & $0.014 *(-0.001$ to 0.013$)$ & 0.006 & 2.3 \\
\hline Age $70-79$ & $0.038^{* *}(0.026$ to 0.049$)$ & 0.006 & 6.07 \\
\hline Age $80-89$ & $0.071 * *(0.055$ to 0.087$)$ & 0.008 & 8.49 \\
\hline Nineties and Over & $0.137^{* *}(0.107$ to 0.167$)$ & 0.015 & 9.36 \\
\hline Private & $-1.024^{* *}(-1.363$ to -0.685$)$ & 0.172 & -5.95 \\
\hline NHS Treatment Centre & $-0.115^{*}(-0.200$ to -0.030$)$ & 0.043 & -2.67 \\
\hline Foundation Trust & $-0.053^{* *}(-0.090$ to -0.016$)$ & 0.019 & -2.79 \\
\hline Teaching Hospital & $0.028(-0.017$ to 0.073$)$ & 0.023 & 1.21 \\
\hline Specialist & $-0.020(-0.052$ to 0.092$)$ & 0.037 & -0.55 \\
\hline Tuesday & $-0.030^{* *}(-0.041$ to -0.018$)$ & 0.006 & -4.68 \\
\hline Wednesday & $-0.043^{* *}(-0.057$ to -0.029$)$ & 0.007 & -6.3 \\
\hline Thursday & $-0.058^{* *}(-0.070$ to -0.046$)$ & 0.006 & -9.08 \\
\hline Friday & $-0.087^{* *}(-0.102$ to -0.071$)$ & 0.008 & -10.81 \\
\hline Saturday & $-0.455^{* *}(-0.485$ to -0.0425$)$ & 0.015 & -30.56 \\
\hline Sunday & $-0.564^{* *}(-0.609$ to -0.519$)$ & 0.023 & -24.09 \\
\hline Observations & $5,288,604$ & & \\
\hline Pseudo $\mathrm{R}^{2}$ & 0.026 & & \\
\hline Wald Chi2(61) & 3948.33 & & \\
\hline Log Pseudolikelihood & $-701,453.48$ & & \\
\hline
\end{tabular}

Controlling for: Month of admission, area type (city, town, hamlet, village), and ICD-10 diagnosis chapter heading. Reference categories: Deprivation I, White, Forties, Traditional NHS Facility, Monday.

Deprivation quintiles measured using the income component of the 2007 IMD.

Robust standard errors with error terms clustered around trusts.

* Significant at $P<0.05$

** Significant at $P<0.01$

patient admitted to the hospital for an elective procedure in 2007 , more than 160,000 patients had a procedure cancelled after they were admitted to the hospital. Some of these cancellations are undoubtedly unavoidable: for instance if a patient was genuinely too ill for surgery. Our empirical results reveal that 
there is significant scope for policies to reduce the rate of last minute cancelled procedures.

First, the variation in 'last minute' cancellation rates between hospitals and between types of hospitals suggests that there is significant room for lowering the rate of cancelled elective procedures at under-performing hospitals. For example, Foundation Trusts are not necessarily attracting healthier patients than traditional NHS providers, but nevertheless, Foundation Trusts, on average, have significantly lower rates of cancellations than traditional NHS providers or academic centres. Similarly, there are multiple examples in our data of two similarly sized NHS trusts which have fivefold differences in their cancellation rates. This type of variation cannot all be the result of patient population alone. This dramatic variation suggests that there are remediable factors that influence the rate of 'last minute' cancellations.

The most obvious is the variation by day of admission. Patients scheduled for procedures on a Monday were significantly more likely to have a procedure cancelled than patients with a procedure scheduled during the rest of the week. This trend arise because time is spent on Mondays addressing patients who were admitted over the previous weekend, or because patients admitted over the weekend are occupying postoperative beds. Either way, as discussed later, this result lends itself to direct policy intervention, which could reduce the rate of cancellations.

The variation in cancellation rates between patients suggests clues for predicting which patients may be more likely to have a procedure cancelled. In our analysis, men, patients age 70 and over, patients with longer than average waiting times, and patients from lower socio-economic groups all had a higher likelihood of having a procedure cancelled. This suggests that last minute cancellations could be reduced by specifically targeting these high-cancellation groups. Existing research suggests that nurse or physician led preassessment clinics reduce the rate of cancelled operations ${ }^{6,22-25}$ and the National Institute for Health and Clinical Excellence (NICE) has issued guidance to this affect. ${ }^{26}$ Trusts are gradually introducing such interventions to tackle this problem, but these interventions may have more impact if they are specifically targeted at the high-cancellation groups identified in this research.

By replacing the S22 tariff with a small tariff for preassessment visits, trusts can be incentivized to introduce clinics while remaining budget neutral on a national scale. The types of cancellations that pre-assessment clinics would prevent are the ones that are most likely to lead to resources being under-utilized (e.g. theatres left empty) and are therefore more costly to hospitals. Whether these clinics are cost-effective needs further study.
The S22 tariff is part of the Payment By Results programme, which was implemented to increase activity in the NHS and help drive down waiting times. ${ }^{17}$ On the whole, Street et al. have previously found that since the introduction of PBR, productivity in the NHS has increased. ${ }^{18}$ Certainly cost of care, as proxied by length of stay, reduced after the introduction of PbR. ${ }^{19}$ At the essence of Payment by Results is reimbursement for procedures performed by a provider. However, the S22 tariff does not reimburse providers for the cost of their activity.

When procedures are cancelled for clinical or other patient reasons, resources are likely to be left idle as a result, and the opportunity cost of that cancellation is far greater than the $£ 432$ reimbursement. This is socially wasteful as another patient could have been treated and the hospital is reimbursed less than the true cost of that cancellation. The actual cost of cancellation will be dependent upon the type of procedure that was due to be carried out and anticipated length of stay of the patient. In this case, providers should be reimbursed for the true cost of not performing the procedure if we believe that they should be compensated for their loss in 'revenue'.

The literature, however, points to non-clinical reasons being the largest cause of last minute cancellations. In these cases, the total cost is likely to be greater than the reimbursement (e.g. the patient and family taking the day off work) but hospitals are reimbursed for this while patients are not. In these circumstances, it is likely the S22 tariff is greater than the hospital's cost resulting from the last minute cancellation as the hospital is reimbursed for procedures performed on other patients. This is wasteful. Further, the tariff acts as a disincentive to reduce non-clinical cancellations because the hospital is reimbursed and gets paid for the procedure they actually perform. In addition, if providers attempt to reduce non-clinical cancellations by reducing the number of planned procedures on a Monday they could end up with idle time and a loss of income.

To make matters worse, in some cases the tariff for a cancelled procedure is larger than the tariff for the scheduled procedure itself. According to the 20072008 NHS Admitted Patient Mandatory Tariff, hospitals receive a greater reimbursement for canceling a minor endoscope procedure on the bladder or diagnostic procedures on the stomach, rather than performing them. ${ }^{20}$ It is clear that the S22 tariff is problematic and not fit for purpose.

These results raise a number of policy issues. First, there should be a review of the S22 tariff. In cases where the procedures are cancelled for non-clinical reasons, the current tariff is likely to be greater than the true cost and is no incentive to reduce these cancellations. There is also an incentive to cancel operations with associated tariffs lower than the S22 tariff. 
In cases, where operations are cancelled for clinical reasons hospitals are likely exposed to costs much greater than the $£ 432$ reimbursed largely resulting from the opportunity cost of resources being left idle. A single S22 tariff does not appear to be appropriate.

Recently, the Department of Health announced that from 2010/11 local commissioners will have flexibility over the S22 tariff. While this is welcome, this budget could be used for interventions designed to reduce clinical cancellations. For example, paying to administer and improve pre-assessment clinics. Further, our research suggests that such interventions should be targeted specifically on the high-cancellation groups including men, patients over 70 and patients from lower socioeconomics groups. Further research to understand why these groups have higher cancellations rates would be informative.

Finally, the results indicate that cancellation rates are higher on Mondays. A potential response would be to reduce the number of planned procedures scheduled for Mondays to accommodate the spill over from weekends. There is obviously a balance between not having enough patients booked for surgery (and therefore the risk of leaving resources idle) and having too many patients booked for surgery (and therefore the risk of last minute cancellations). Closer investigation of trends within individual hospitals may be instructive for managers.

\section{Conclusions}

The NHS has received criticism in recent years over cancelled procedures and has responded by improving the measurement of cancelled procedures and developing mechanisms to rebook cancelled patients quickly. Despite these improvements, one in 30 operations were cancelled in 2007 imposing a considerable cost on hospitals and/or patients. This paper has identified a number of avenues for further investigation, which may help organizations to reduce this cancellation rate.

Firstly, there is considerable variation in cancellation rates by type of provider, which given the patient level and case level controls introduced, indicate that Foundation Trusts and private providers have lower cancellation rates. This should be investigated further. Secondly, our findings indicate there are patient characteristics which predict the likelihood of an operation being cancelled. The underlying causes of these should be explored further, and interventions designed to reduce cancellation rates should be targeted specifically at these groups. Finally, the S22 tariff itself is not fit for purpose. It rewards hospitals for non-clinical cancellations which is wasteful, and disincentivizes hospitals to reduce this rate. Further, it does not cover the true costs of cancellations where resources are left idle.

\section{Acknowledgements}

We thank the editor and the reviewers for their insightful and constructive comments on the original draft.

\section{References}

1 Department of Health. Cancelled Operations - FAQ Available at http://www.dh.gov.uk/en/Publicationsandstatistics/ Statistics/Performancedataandstatistics/Cancelledoperations/ DH_090038. (last accessed 10 April 2009) 2009

2 Lacqua M, Evans J. Cancelled elective surgery: an evaluation. The American Surgeon 1994;60:3

3 Tait AR, Voepel-Lewis T, Munro HM. Cancellation of Pediatric Outpatient Surgery: Economic and Emotional Implications of Patients and Their Families. Journal of Clinical Anaesthesiology 1997;9:213-19

4 Ivarsson B, Kimblad PO, Sjoberg T, Larsson S. Patient reactions to cancelled or postponed heart operations. Journal of Nursing Management 2002;10:75-81

5 Mangran JL. Total Joint Replacement: Implication of Cancelled Operations of Hospital Costs and Waiting List Management. Quality in Health Care 1992;1:34-37

6 Asimakopoulos G, Harrison R, Magnussen PA. Pre-admission clinic in an orthopaedic department: evaluation over a 6-month period. Journal of the Royal College of Surgeons of Edinburgh 1998;43:178-81

7 Lee CS, McCormick PA. Telephone Reminders to Reduce Non-Attendance Rate for Endoscopy. Journal of the Royal Society of Medicine 2003;96:547-51

8 Rai MR, Pandit JJ. Day of surgery cancellations after nurse-led pre-assessment in an elective surgical centre: the first 2 years. Anaesthesia 2003;58:692-9

9 Schofield WN, Rubin GL, Lai YY, Sindhusake D, Fearnside M, Klineberg PL. Cancellation of Operations on the Day of Intended Surgery at a Major Australian Referral Hospital. Medical Journal of Australia 2005;182:612-15

10 Ferschi MB, Tung A, Sweitzer B, Huo D, Glick DB. Preoperative Clinics Visits Reduce Operating Room Cancellations and Delays Anesthesiology 2005;103:855-60

11 Kennedy MJ. An exploratory study of the responses of the patient to the cancellation of his surgery. International Journal of Nursing Studies 1969;6:121-32

12 Dexter F, Marcon E, Epstein R, Ledolter J. Validation of Statistical Methods to Compare Cancellation Rates on the Day of Surgery. Anesth Analg 2005;101:13

13 Pollard J, Zboray A, Mazze R. Economic benefits attributed to opening a preoperative evaluation clinic for outpatients. Anesth Analg 1996;83:7

14 van Klei W, Moons K, Rutten C, et al. The effect of outpatient preoperative evaluation of hospital inpatients on cancellation of surgery and length of stay. Anesth Analg 2002;94:5

15 Sanjay P, Dodds A, Miller E, Arumungam P, Woodward A. Cancelled elective operations: an observational study from a district general hospital. Journal of Health Organisation and Management 2007;21:5

16 McWhinnie DL, Michaels JA, Collin J, Morris PJ. Resource implications of cancelled operations. BMJ (Clinical Research Ed 1994;308:138-9

17 NHS Information Centre. On-line HRG v 3.5 Explorer. Available at http://www.ic.nhs.uk/default.asp?sID $=1175608$ 836820. (last accessed 14 April 2009) 2009

18 Department of Health. Payment By Resutls: Tariff Information - http://www.dh.gov.uk/en/Managingyour organisation/Financeandplanning/NHSFinancialReforms/ 
DH_077279. (last accessed 10 February 2009) Department of Health, 2007

19 Deparment of Communities and Local Government. Indices of Deprivation 2007. http://www.communities.gov.uk/com munities/neighbourhoodrenewal/deprivation/deprivation07/ (last accessed 25 January 2009)

20 Jordan H, Roderick P, Martin D. The Index of Multiple Deprivation 2000 and accessibility effects on health. Journal of epidemiology and community health 2004;58:250-7

21 Department of Health. NHS Foundation Trusts Webpage http://www.dh.gov.uk/en/Healthcare/Secondarycare/NHS foundationtrust/DH_072543. (last accessed 2 August 2009) Department of Health

22 el Naggar M, Welsh A, Dickenson AJ, Flood LM, Gibb JG. Pre- admission clinics in ENT: a national audit of UK practice and opinion. The Journal of Laryngology and Otology 1997;111:357-60

23 Knox M, Myers E, Wilson I, Hurley M. The Impact of Pre-Operative Assessment Clinics on Elective Surgical Case Cancellations. The Surgeon 2009;7:76-78

24 Reed M, Wright S, Armitage F. Nurse-led general surgical pre-operative assessment clinic. Journal of the Royal College of Surgeons of Edinburgh 1997;42:310-3

25 Samuel PR, Ranta M. A paediatric otolaryngology pre-admission assessment clinic audited. The Journal of Laryngology and Otology 2001;115:723-6

26 National Institue for Clinical Excellence. Clinical Guideline for Preoperative Tests: The Use of Routine Preoperative Tests for Elective Surgery. Available at http://www.nice.org. uk/Guidance/CG3. (last accessed 10 April 2009), 2003 